\section{Correspondence on 'What comes after the lockdown? Clustering of ANCA-associated vasculitis: single-centre observation of a spatiotemporal pattern'}

We read with great interest the recent article by Gauckler et al reporting 15 patients diagnosed with antineutrophil cytoplasm antibodies-associated vasculitides (AAV) during the COVID-19 pandemic between February and August 2020. During this period, the authors report an incidence shift with a COVID-19 gap of no diagnosed AAV cases during the lockdown period in March and April 2020, followed by a postlockdown phase in the subsequent 4 months and an increased incidence rate. ${ }^{1}$ Diagnosis of AAV can be delayed during the COVID-19 pandemic because non-urgent tests and visits might have been postponed due to closure of medical services during the lockdown. We here report a single-centre observation in 28 patients diagnosed AAV with kidney involvement requiring renal biopsy in 2019 and 2020 (until 16th of December). ${ }^{12}$

Between January and December 2020, a total number of 11 patients required renal biopsy confirming AAV with kidney involvement (figure 1A). Compared with 2019, we observed a COVID-19 gap in April to June 2020 with a postlockdown increase of incidence rates in diagnosed AAV with renal biopsy (figure 1A). Interestingly, the COVID-19 gap preferentially affected AAV patients admitted to the normal medical ward (figure 1B). In contrast, no such COVID-19 gap was observed in critically ill patients requiring intensive care unit (ICU) or intermediate care unit (IMC) supportive care (figure 1C). These findings are in line with previous observations that the COVID-19 pandemic has significant impact on patients with diseases other than COVID-19, especially in cases admitted to the normal medical ward. ${ }^{3}$

\section{A}

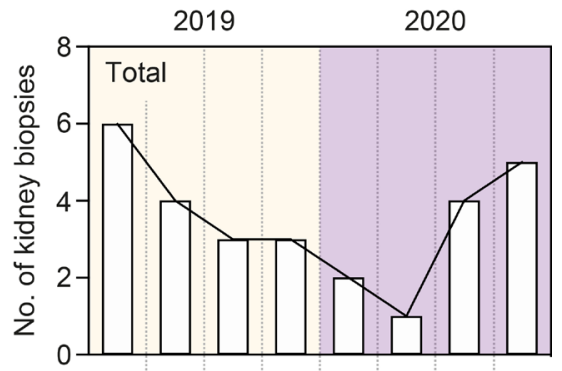

B

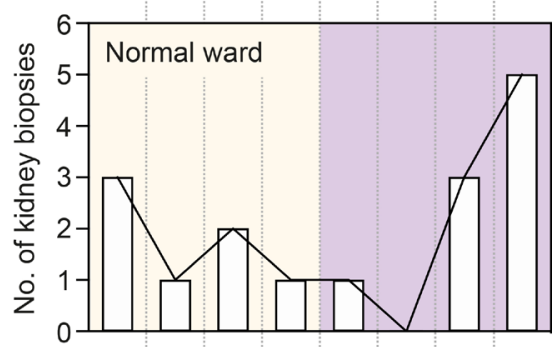

C

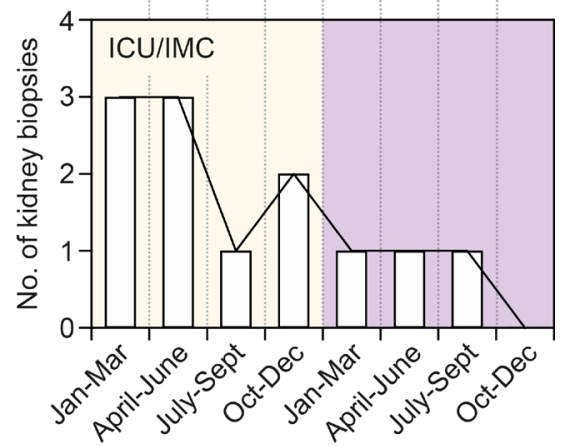

Figure 1 Timeline of incident ANCA-associates vasculitis cases confirmed by renal biopsy in 2019 and 2020. ANCA, antineutrophil cytoplasm antibodies; ICU, intensive care unit; IMC, intermediate care unit.
Prompt diagnoses of AAV with renal involvement currently affected by the ongoing COVID-19 pandemic are crucial in the disease management. Although definite conclusions on long-term clinical outcomes cannot be yet drawn, our observations indicate no detrimental effects of the COVID-19 pandemic on critically ill patients requiring ICU/IMC supportive care. In contrast, the COVID-19 pandemic resulted in delayed renal biopsy and diagnosis of AAV in patients admitted to the normal medical ward. Recent studies in the second trimester of 2020 during the COVID-19 pandemic reported patients with diagnosed AAV whom renal replacement therapy was necessary in seven of nine patients. Although all patients received remission induction therapy, none returned to normal renal function and one patient died. According to literature, AAV is preceded by a prodromal phase characterised by constitutional symptoms, eventually more affecting patients admitted to the normal medical ward. ${ }^{4}$ Diagnostic delay at this stage is common and has been demonstrated to be associated with mortality and end-stage renal disease ${ }^{56}$ During the COVID-19 lockdown, containment measures and fear may have contributed to downplay constitutional symptoms and to underestimate their need for medical attention in AAV patients. Since the COVID-19 pandemic resulted in delayed renal biopsy and diagnosis of AAV in patients admitted to the normal medical ward in our single-centre observation, the COVID-19 pandemic should be regarded as a risk factor especially in patients with diseases other than COVID-19 and presenting with constitutional symptoms.

\section{Samy Hakroush, ${ }^{1}$ Björn Tampe ${ }^{2}$}

${ }^{1}$ Institute of Pathology, University Medical Center Göttingen, Göttingen, Germany ${ }^{2}$ Department of Nephrology and Rheumatology, University Medical Center Göttingen, Gottingen, Germany

Correspondence to Dr Björn Tampe, Department of Nephrology and Rheumatology, University Medical Center Göttingen, 37075 Gottingen, Germany; bjoern.tampe@med.uni-goettingen.de

Contributors BT conceived the correspondence, collected and analysed data and wrote the first draft. SH participated in the construction and editing of the manuscript.

Funding The authors have not declared a specific grant for this research from any funding agency in the public, commercial or not-for-profit sectors.

Competing interests None declared.

Patient and public involvement Patients and/or the public were not involved in the design, or conduct, or reporting, or dissemination plans of this research.

Patient consent for publication Not required.

Provenance and peer review Not commissioned; internally peer reviewed.

(c) Author(s) (or their employer(s)) 2021. No commercial re-use. See rights and permissions. Published by BMJ.

\section{Check for updates}

To cite Hakroush S, Tampe B. Ann Rheum Dis Epub ahead of print: [please include Day Month Year]. doi:10.1136/annrheumdis-2020-219687

Received 9 December 2020

Accepted 10 December 2020

\section{Linked}

- http://dx.doi.org/10.1136/annrheumdis-2020-219696

Ann Rheum Dis 2021:0:1-2. doi:10.1136/annrheumdis-2020-219687

ORCID iD

Björn Tampe http://orcid.org/0000-0002-4357-9863

\section{REFERENCES}

1 Gauckler P, Bettac EL, Nairz M, et al. What comes after the lockdown? clustering of ANCA-associated vasculitis: single-centre observation of a spatiotemporal pattern. Ann Rheum Dis 2020. doi:10.1136/annrheumdis-2020-219212. [Epub ahead of print: 01 Dec 2020].

2 Giollo A, Bixio R, Gatti D, et al. Challenge of diagnosing ANCA-associated vasculitis during COVID-19 pandemic: a missed 'window of opportunity'. Ann Rheum Dis 2020. doi:10.1136/annrheumdis-2020-218830. [Epub ahead of print: 19 Aug 2020].

3 Metzler B, Siostrzonek P, Binder RK, et al. Decline of acute coronary syndrome admissions in Austria since the outbreak of COVID-19: the pandemic response causes cardiac collateral damage. Eur Heart J 2020;41:1852-3. 
4 Monti S, Craven A, Klersy C, et al. Association between age at disease onset of antineutrophil cytoplasmic antibody-associated vasculitis and clinical presentation and short-term outcomes. Rheumatology 2020. doi:10.1093/rheumatology/keaa215. [Epub ahead of print: 23 May 2020].
5 Koldingsnes W, Nossent H. Predictors of survival and organ damage in Wegener's granulomatosis. Rheumatology 2002;41:572-81.

6 Houben E, Groenland SL, van der Heijden JW, et al. Relation between duration of the prodromal phase and renal damage in ANCA-associated vasculitis. BMC Nephrol 2017; $18: 378$. 